* Corresponding author

Phone +421556023513

E-mail address: ildiko.mankova@tuke.sk (IIdiko

Maňková, prof., Ing., (SC.)

Article information

Article history: AMS-Volume15-No.3-00113-11

Received 05 April 2011

Accepted 18 May 2011

\section{Outline of FEM Simulation and Modelling of Hard Turning Process}

\author{
Ildiko Maňková a*, Pavel Kovac ${ }^{b}$, János Kundrak c, Jozef Beňo ${ }^{d}$ \\ a Full professor at TU Košice, KTaM SjF TU, Masiarska 7404001 Košice, Slovakia \\ ${ }^{b}$ Full professor at University Novi Sad, Serbia \\ 'Full professor at University Miskolc, Hungary \\ ${ }^{d}$ Associate professor at TU Košice, Slovakia
}

\section{BIOGRAPHICAL NOTES}

Ildiko Maňková, prof. Ing. CSc., since 2005 works as a full professor at the Faculty of Mechanical Engineering TU Košice, Department of Materials and Technology. She is graduated as MSc. and received PhD degree in Production Engineering at TU Kosice, Research orientation is in the area of metal cutting, tool condition monitoring and machined surface quality assessment. She has been a principal investigator and contractor of national and international projects (VEGA, Ceepus Tempus, Socrates) and she is a member of consortium of 7th FP-ACCENT oriented to the problems of machined surface integrity in aero engine components. She has a wide cooperation with universities of technology abroad such as Vienna, Brescia, Coventry, Magdeburg, Budapest, Miskolc, Opole and Cracow. She was awarded as professor honoris causa Facultatis Mechanicae Universitas Miskolciensis. She is author and co-author of two books and over 75 papers published in national and international journals and proceeding from conference.

Pavel Kovac, prof. Dr. full professor at the Faculty of Technical Science Univeristy of Novi Sad Serbia, he is chief of Laboratory for metal cutting at of Production Engineering faculty of technical Science, University of Novi Sad. He is graduated as MSc. and received PhD degree in Production Engineering at University of Novi Sad. Area of research orientation is metal cutting phenomena such as surface roughness, tool wear, cutting temperature and cutting forces, significant contribution he has in the area of process monitoring and sensor development. He has been principal investigator in more than 15 research projects. He was visiting professor on Prince of Sonkla University in Hatyai Thailand. He is author and co-author of three books, four text books and more than 120 papers published in national and international journals and proceeding from conference.

Janos Kundrak, prof. DrSc. professor and doctor of science at the Faculty of Mechanical Engineering and Informatics Miskolc University, Hungary, he is Head of Department of Production Engineering. He is graduated as MSc. at Miskolc University and received PhD degree in Production Engineering at Charkov University, Ukraina. Area of research orientation is hard machining phenomena such as surface roughness, tool wear and cutting forces, significant contribution he has in the area superhard tool material application. He has been principal investigator in more than 10 research projects (OTKA). He has a wide cooperation with universities of technology abroad such as Vienna, Magdeburg, Athens and Cracow as well as with industrial companies in Hungary. He is author and co-author of more than 150 papers published in national and international journals and proceeding from conference.

Jozef Beňo, MSc. PhD. (born 1952) works at Department of Technology and Materi- 
als, Faculty of Mechanical Engineering TU Košice. The first degree obtained in 1977 and followed by PhD graduation in 1984. Since 1994 he has been a senior lecturer in mechanical technology at TU Košice. In 2002 - 2010, he has been Member of Slovak commission for graduation in technology and materials. Scientific activity: machinability of advanced materials, tool performance, coordinator of national projects in advanced technology research. International cooperation in research of innovative technology: research programme between Germany and Slovakia since 2001. He is head of international research projects with universities in Hungary (Budapest) and Poland (Krakow) in the field of tool testing, surface roughness research, free form milling, etc. Author of three books devoted to the metal cutting principles and about 40 journal papers on the same subject.

\section{KEY WORDS}

Hard Turning, Cutting Force, Temperature, Advant Edge Modelling

\section{ABSTRACT}

Hard machining, as attractive replacement for many rough and finish grinding operation, generates high cutting forces and temperature that enhance tool wear when act together. Therefore, the tool geometry and machining parameters have to be carefully optimized for a given material. Because of high cost and time consuming experimental work up-to-date advanced software for modeling and simulation brings quick and adequate solution. The aim of this contribution is to study the influence of cutting parameters and material hardness on accompanying phenomena when hard turning process with mixed oxide ceramic inserts. Hardened steel with different hardness level of HRC 46, HRC 55 and HRC 60, respectively, has been employed in modeling and trials. In order to better understand dynamics of cutting hardened steel, investigation has been performed making use finite element simulation in two dimension, and experimental analysis of cutting force. The potentiality of the model as well as the experimental results are compared and discussed.

\section{Introduction}

Hard turning is a complex process with chip formation occurring at tool nose radius and relative small feed and depth of cut. A thorough analysis of this innovative technology will improve the process capability greatly. Most research on hard turning in the literature is limited to experimental work, while practical theoretical models including FEA (finite element analysis) of this promising machining process are scarce, due to the inherent complexity of a hard turning process. In order to improve the fundamental understanding of hard turning and process optimization for producing favourable surface integrity, theoretical modelling of a hard turning process has economic as well as scientific importance $[3,7]$. The finite element method seems to be the right tool to predict cutting performance including chip flow and morphology, cutting forces, and complex residual stress and cutting temperature fields which are often beyond the capability of current measurement methods. A 2D FEA modelling of temperature and forces in orthogonal cutting of hardened steel was reported more times $[1,2,5,9]$. Nowadays variety of applicable FEM modelling software is available. The choice of finite element software for machining analysis is an important factor in determining the quality and scope of analysis that can be performed.

One of this software ThirdWave System's AdvantEdge is a machining specific FEM package. It has pre-programmed modules for both 2D and 3D machining operations including turning and milling. AdvantEdge also comes with a workpiece modeller as well as a material property library.

As AdvantEdge has been explicitly written with machining operations in mind, its solvers have been optimized specifically for metal-cutting processes. Also, the software has a very user friendly interface with simple input screens to supply the tool and workpiece geometries as well as the process parameters, Fig. 1. AdvantEdge has a built-in editor for simple tool and workpiece geometries and allows for the import of more complex geometries. AdvantEdge also has a very extensive material library with models of many engineering metals and alloys, including several aerospace alloys [2]. Specifying new materials is relatively simple and the user has the capability to enter the properties of the material using different models. The program also uses adaptive meshing to handle increase the accuracy of the solution in the areas of high deformation and allows a reasonable degree of flexibility in the meshing controls $[4,6,13]$. 


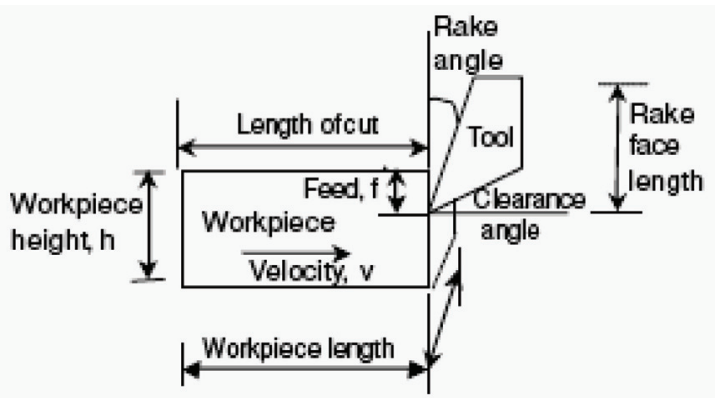

Fig. 1: Input tool and wokpiece geometry to the orthogonal cutting model.

On the other hand AdvantEdge does not give the user much flexibility in configuring the controls of the solver. While this may be preferable in some cases, this means that the user is restricted to the preset controls of the software. If a quick, easy to setup machining simulation is needed, then the preferable software packages would be AdvantEdge. This package allows quick setup of simulations and has built in modules to specify material properties, tool and workpiece geometries and process parameters, Fig. 2.

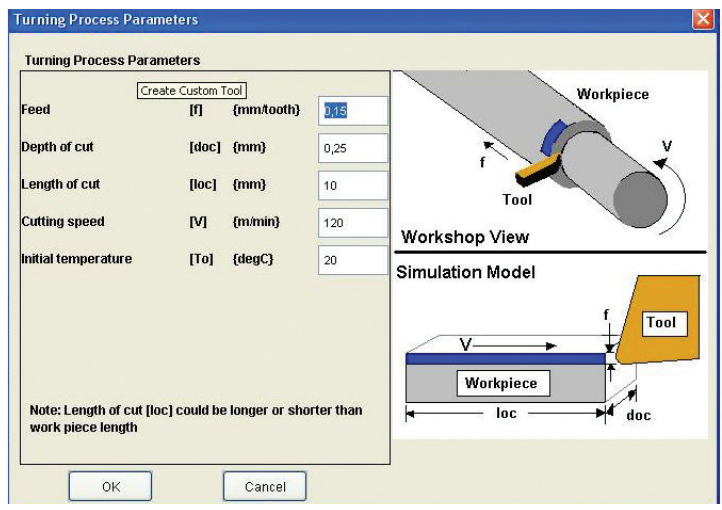

Fig. 2: Example of one of the input set up window.

In this study a general practical 2D model has been applied to analyze hard turning steel with three different types of hardness HRC 46, HRC 55 and HRC 60, using mixed oxide ceramic cutting tool. The goal of this study is to investigate the influence of cutting parameters and material hardness on the accompanying phenomena of hard turning process - cutting force and temperature. Experimental evidence and simulation results are compared.

\section{HARD TURNING - Definition of input parameters FOR Modelling}

Machining conditions in hard turning are different from conventional turning. Depth of cut, feed rate, and cutting tool nose radius are typical finishing conditions in hard turning. Because of the low depth of cut and the large cutting tool nose radius, chip formation usually takes place in the nose radius or on the chamfer of a cutting tool. Thrust force appears to be the largest force component, while the feed force component is the smallest one using a worn tool. By increasing the tool flank wear, a significant rise of the thrust force component can be observed. Considering a very small contact area on the tool-chip interface, extremely high stresses and temperatures develop on the area. A numerical simulation may provide a powerful tool to analyze the contact mechanics on the tool/chip and tool/workpiece interfaces $[3,8]$.

Cutting temperature is of fundamentals importance in hard turning. Cutting temperature may cause thermal damage and even white layer when machining hardened steels. The influence of cutting temperature on the surface integrity may be more important than the tool life. However, the fact that temperature is most difficult to measure explains the numbers of different methods used over the years $[7,14]$.

In this study a 2-dimensional version of software AdvantEdge has been used for simulation. The finite element model is composed of workpiece and a tool. Workpiece is defined as a deformable body while the tool is considered as a rigid. A user defined geometry and cutting edge radius parameterizes the cutting tool. The tool penetrates through the workpiece at constant speed and constant feed rate. Material properties are essential inputs for any FEM simulation and other analytical modelling of a machining process. The applied software employs well-known Johnson-Cook material model to describe material behaviour. Friction on the tool-chip interface is a major input determining the dependent variables such as chip morphology, cutting forces, residual stresses, and temperatures. Therefore, an accurate determination of the friction condition is of considerable importance for finite element analysis of metal cutting. Friction conditions at the tool/chip interaction was modelled by using an average friction coefficient only determined by Coulomb's friction law as a value of 0,5. It limits ap- 
plication of the model and reduces FEA model efficiency significantly $[7,10]$.

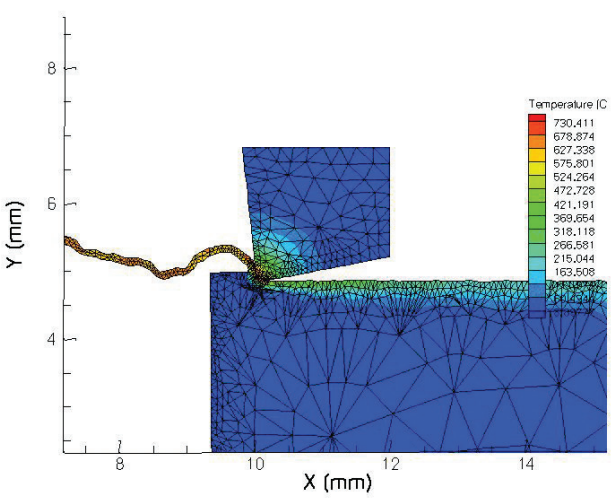

Fig. 3: Example of graphical output from temperature simulation.

A Lagrangian finite element-based machining model is applied in the simulation of cutting force components and temperature in two-dimensional turning of hardened steel. The cutting force Fc force in $\mathrm{X}$ direction $\left(\mathrm{F}_{\mathrm{X}}\right)$ and transverse force in $\mathrm{Y}$ direction $\left(\mathrm{F}_{\mathrm{Y}}\right)$ on the tool are displayed as functions of time. In simulation with AdvantEdge, there is no separation criteria defined since chip formation is assumed to be due to plastic flow; therefore the chip is formed by continuously remeshing the workpiece. Adaptive remeshing of the model is used to avoid extreme element distortions due to the strong deformations. It remeshes the workpiece periodically to refine large elements, re-mesh distorted elements, and coarsen small elements. Heat transfer to the tool is allowed, Fig. 3, but heat transfer by radiation, convection or conduction was considered as negligible. The model is discredited by triangular elements and uses maximum 12000 elements, depending on the chip configuration [11]. The length of cut was set to $5 \mathrm{~mm}$. The simulation was conducted with coolant off and initial temperature was fixed at $20^{\circ} \mathrm{C}$. The simulation was conducted in rapid mode.

\section{Experimental Conditions and Model Validation}

For simulation, workpiece material AISI 1045 hardened at hardness 46, 55 and 60 HRC, respectively, have been employed. Turning process was conducted with mixed oxide ceramics insert D310 $\left(70 \% \mathrm{Al}_{2} \mathrm{O}_{3}+30 \% \mathrm{TiC}\right)$ with a SN geometry, nose radius $r_{\varepsilon}=0,8 \mathrm{~mm}$, and chamfered edge $0,2 \times 20^{\circ}$, $\gamma=-6^{\circ}, \alpha=6$. Set of cutting conditions are fol- lows: cutting speed $\mathrm{v}_{\mathrm{c}}=90,120$, and 150, 240 and $350 \mathrm{~m} / \mathrm{min}$, feed rate: $\mathrm{f}=0,047,0,1,0,15$ and 0,2 $\mathrm{mm}$, depth of cut: $\mathrm{a}_{\mathrm{p}}=0,5 \mathrm{~mm}$.

In this study, external longitudinal turning of hardened steel of hardness 55HRC had been employed for measurement of cutting force components $F_{c}, F_{f}, F_{p}$ by triaxial dynamometer. The difference between the simulated values and the experimental ones did not exceed 10\% [11]. These differences could be caused by different way of cutting 2D in simulation and 3D in measurement. 2D simulation is unable to make punctual estimation of thermo mechanical stress induced on the material/tool interface therefore modeled and simulated outputs from software has only informative character [6]. Comparisons of measured and simulated data are illustrated graphically in Fig. 4.
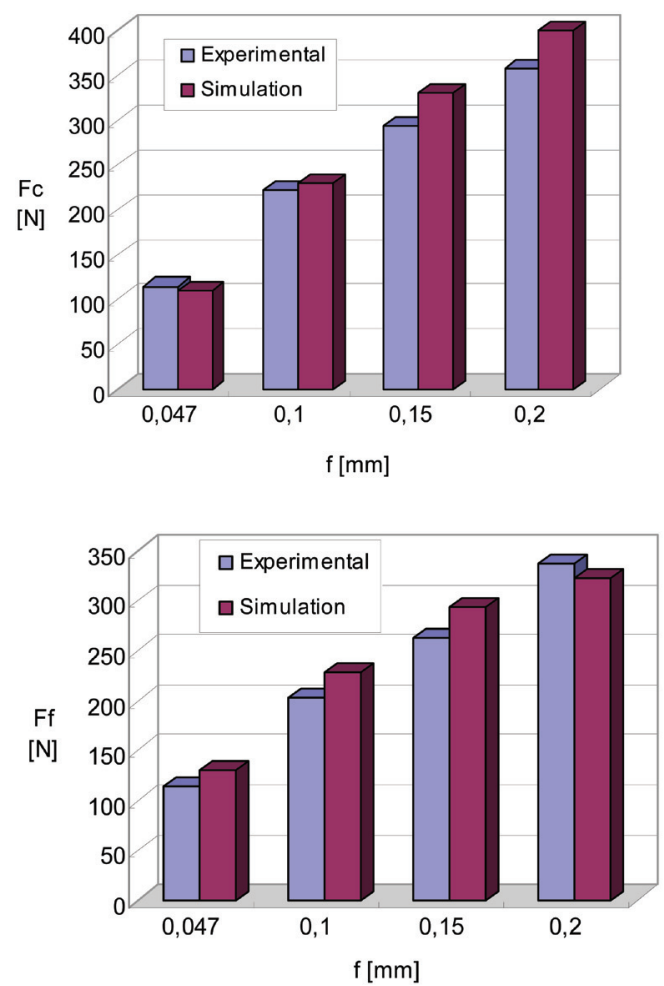

Fig. 4: Comparison of experimental and simulated cutting force values $F C, F f$, for v $=120 \mathrm{~m} / \mathrm{min}$, workpiece hardness $55 \mathrm{HRC}$.

Figure 4 illustrates the cutting force behaviour in function of the feed rate, while the other parameters remain constant. It is interesting to note the linearity of the cutting force within the feed rate range considered. Simulation results have been processed graphically. AdvantEdge software 
shows simulation results in different way such as a table or graph or color area, Fig. 5.

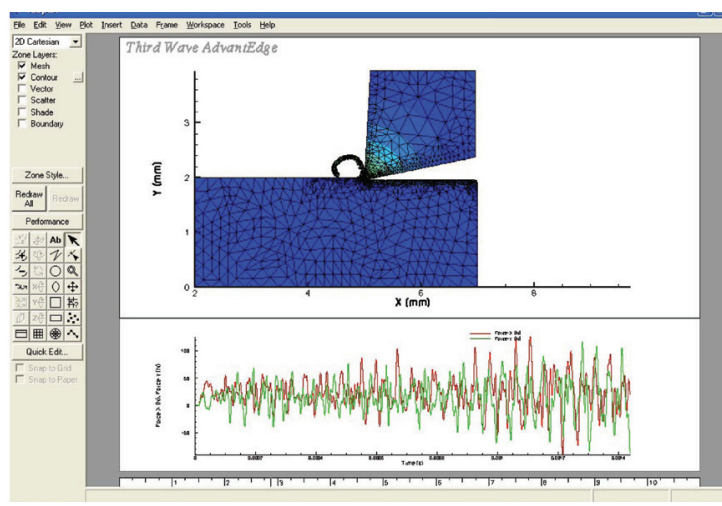

Fig. 5: Example of graphical output from cutting force simulation.

\section{Simulation results and Discusion \\ 4.1 Effect of Cutting Parameters and Material Hardness on Cutting Forces}

Ceramic cutting tools have an advantage in the machining of hard work piece materials at high speed. The variation of main cutting force with cutting speed has been modelled. It can be noted that the cutting forces of the ceramic cutting tool slightly decreases with cutting speed, Fig 6. The decrease of cutting force with respect to cutting speed when using mixed alumina ceramic cutting tool shows that this type of ceramic cutting tool can machine the work piece material with high speed and at low cutting forces. The lower cutting forces result in a lower distortion of work piece, which improves the surface finish while machining with the ceramic cutting tools and particularly by using mixed oxide ceramic cutting tools. The influence of hardness of the workpiece on surface roughness was studied [12], on machining with ceramic cutting tools. It can be noted that the surface roughness slightly increases as the hardness of the work piece material increases. Due to the increase in hardness of the material, greater cutting force is needed to machine the work material. The ceramic cutting tool materials machine the harder work piece material with higher cutting forces than work piece materials with lower hardness. This may contribute to the increase in surface roughness in addition to the other factors such as the increase in cutting temperature, deformation of the nose region of the cutting tool and the serrated chips caught in between the work piece and cutting tool.

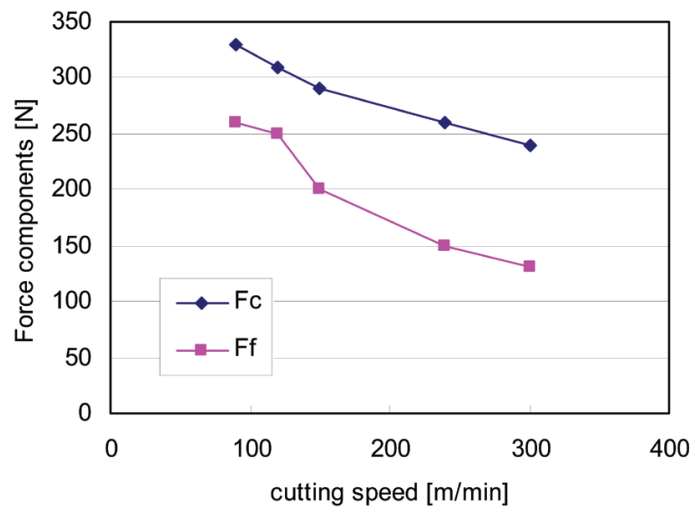

Fig. 6: Numerical results of cutting force component for different cutting speed, $H R C 55, a_{p}=0,5 \mathrm{~mm}, f=0,15 \mathrm{~mm}$.

\subsection{Effect of Cutting Parameters and Material Hardness on chip Deformation}

Besides the cutting and transverse force it is possible to extract from the proposed model predictions for values that it would be very workintensive or even impossible to obtain otherwise. Examples for such cases are: plastic strain rate, chip deformation, von Misses stresses, and temperature distribution and heat rate.

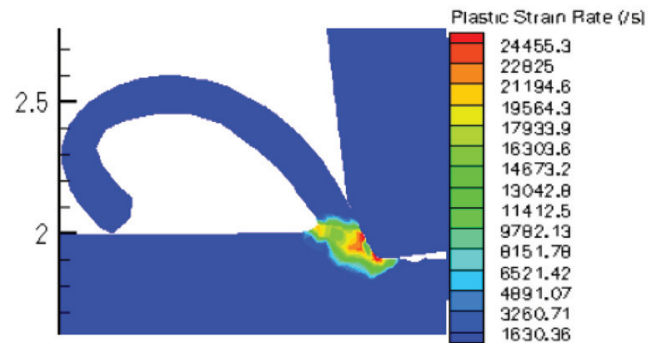

Fig. 7: Example of graphical output from plastic strain rate HRC55.

In Fig. 7 plastic strain rate in shear zone for cutting speed $120 \mathrm{~m} / \mathrm{min}$, is shown. This figure demonstrates the model at a step analysis, for length of cut I=1,2 mm, where cutting is well into the steady-state region.

Effect of material hardness and cutting condition on chip deformation and chip thickness have been modelled, Fig. 8 and Fig. 9.

As illustrate pictures the higher is the hardness of material the lower is chip thickness. The feed more influences the chip thickness than the cutting speed. 


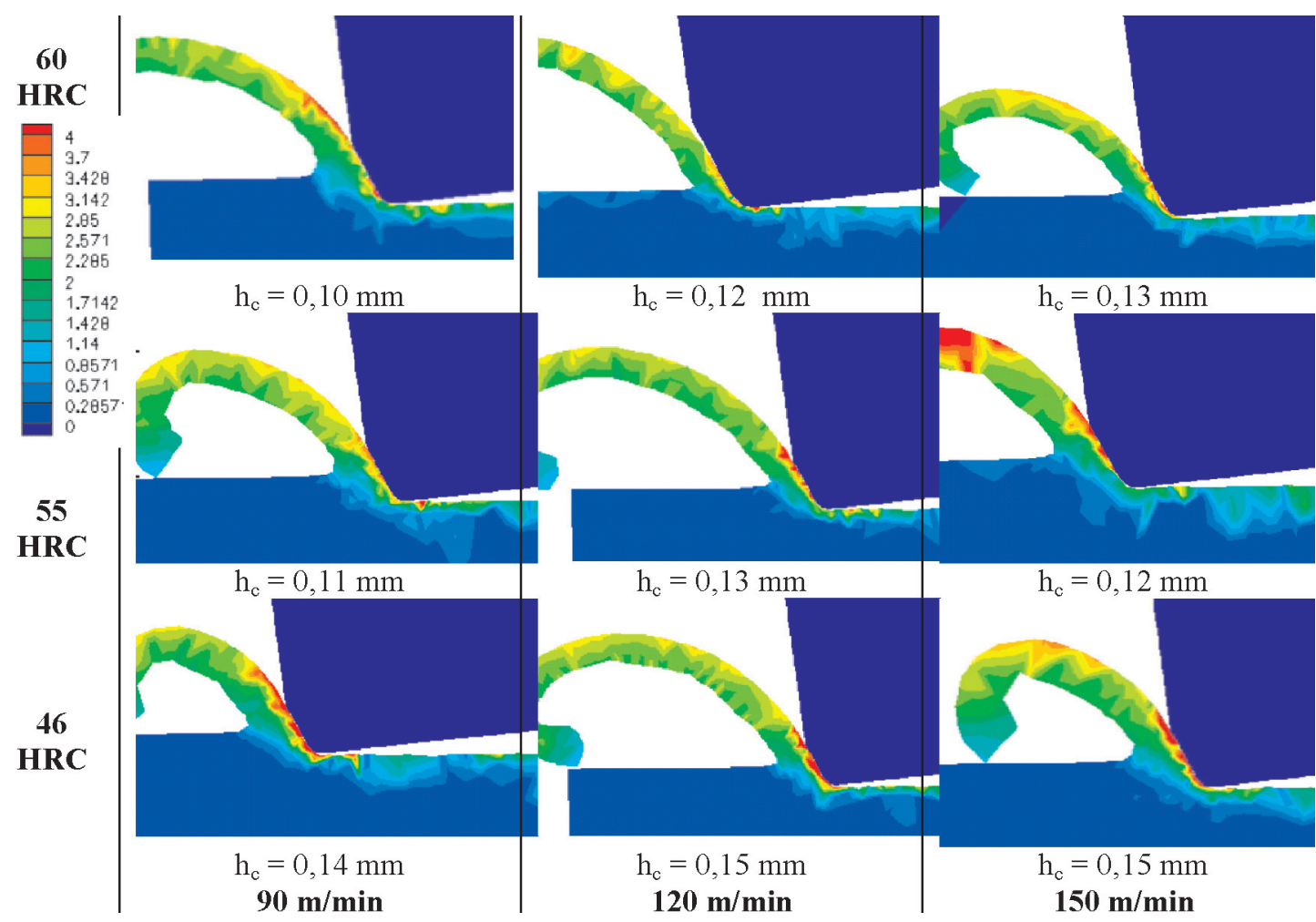

Fig. 8: Effect of material hardness and cutting speed on chip deformation.

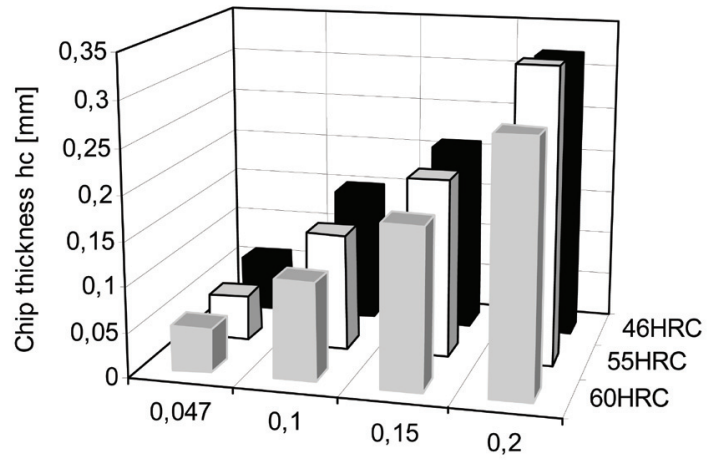

Feed rate $\mathrm{f}[\mathrm{mml}$

Fig. 9: Effect of material hardness and feed rate on chip thickness.

\subsection{Effect of Cutting Parameters and Material Hardness on Cutting Temperature and Heat Flow}

The knowledge of maximum temperature and of the distribution of the temperature field in the rake face of the tool is of great interest because of high temperature in ceramics tool are connected to wear mechanics that reduces the tool life. With the simulated results provided by model it is possible to minimize unwanted effects and to choose suitable cutting condition in order to optimise the process [6].

Considering of low thermal activity of ceramics it is assumed that the temperature distribution on the rake face of the cutting tool is mainly determined by sources of plastic deformation of the metal on the shear plane and by the friction on the tool-chip interface. Heat generation rate due to plastic strain is illustrates on Fig. 10 for material hardness of 55 HRC. Simulation of cutting temperature for different workpiece hardness and cutting speed has been done. Depth of cut $\mathrm{a}_{\mathrm{p}}=0,5 \mathrm{~mm}$ and feed per revolution $\mathrm{f}=0,15 \mathrm{~mm}$ were fixed. Simulation results are processed in Figs. 11 and 12 respectively. Graphs show variation of temperature for three values of cutting speed. Figure 12 represents the temperature distribution on rake face of cutting inserts. As it can be shown on Fig. 12 temperature differences among different cutting speed employed are clearer for hardness of 55HRC and $60 \mathrm{HRC}$ than for hardness of $45 \mathrm{HRC}$ and have the highest value in certain distance from cutting edge. Rake face temperature is growing with increasing of cutting speed and hardness. 


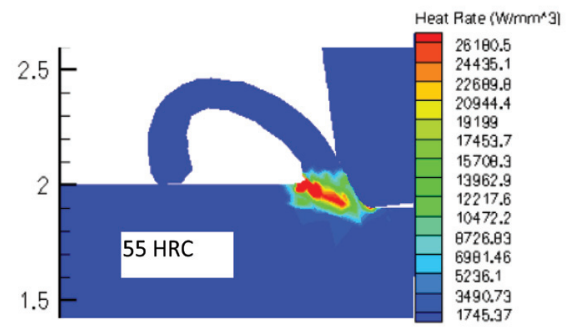

Fig. 10: Graphical output from heat rate in shear area; material hardnesS HRC55.

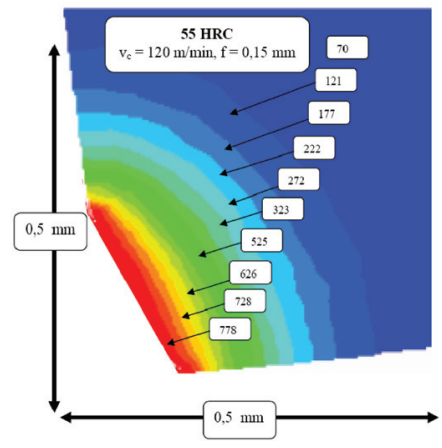

Fig. 11: Temperature distribution on tool rake face.

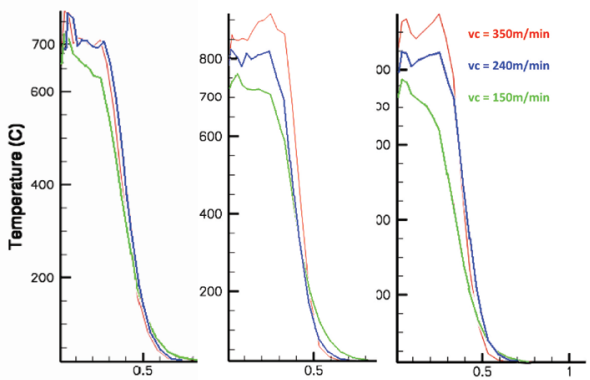

Fig. 12: Temperature vs distance along the tool rake face for different material hardness.

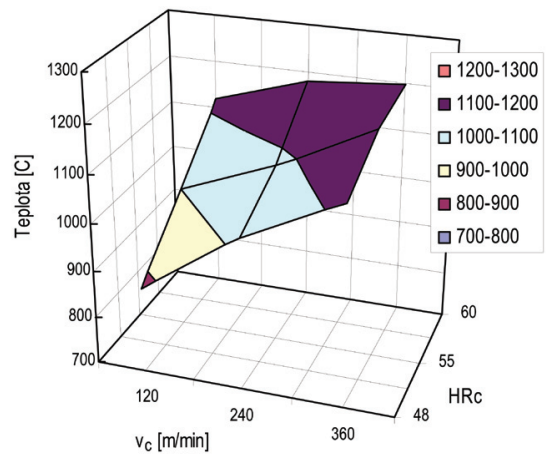

Fig. 13: Influence of cutting speed and workpiece hardness on temperature distribution in ceramic insert rake face area.
Figure 13 illustrates influence of cutting speed and work piece hardness on temperature appearing on tool rake face. It can be shown; there is a strong correlation between temperature and work piece hardness due to chip formation. Consequently, temperature rice accounts quite different progress at chip tool contact due to cutting speed as shown in Fig. 13. Because of low thermal conduction of ceramics, temperature in chip-tool contact assumes peak-like non-uniform distribution when cutting speed varies from 240 to $360 \mathrm{~m} / \mathrm{min}$, a case that is not affected by work piece hardness. Reason is, that non-uniform chip strain rate dissipates temperature at chip-tool contact reducing quickly as chip leaves tool rake.

\section{Conclusion}

Summarizing the results reported above it can be concluded that hard turning has many advantages in comparison to other processes in machining of hardened steels. The finite element methods have been extensively used for modelling machining operations. This method is also used in the present paper and the software AdvantEdge is employed. Simulation of 2D orthogonal cutting model is provided. The modelled results for cutting and transverse force components have been compared with experimentally achieved values. However, other results such as temperature distribution, chip thickness and chip deformation as well as plastic strain rate had been only predicted; because of measuring these data is more time consuming and very work intensive.

From the analysis provided in this contribution can be concluded that the proposed model fits quite well and is suitable for practical application mainly in industry. Therefore FEM simulation software provide very important role in research work because of a minimum amount of experimental work is needed and produce reliable results, allowing for industrial use of optimal production.

\section{Acknowledgement}

Presented results were carried out within Research Grant Projects VEGA No. 1/0378/08 supported by Scientific Grant Agency of the Ministry of Education of Slovak Republic and the Slovak Academy of Science. 


\section{References}

[1] Mackerle, J. (2003). Finite element analysis and simulation of machining: an addendum a bibliography (1996-2002). Int. J Mach Tools Manuf, vol. 43, pp. 103-114

[2] Mackerle, J. (1999). Finite element analysis and simulation of machining: a bibliography (1976-1996). J Mater Process Technol, vol. 86, pp. 17-44

[3] Tonshoff, H.K., Arendt, C., Ben Amor, R. (2000). Cutting of hardened steel. Annals of the CIRP, vol. 49, no.2, pp. 547566

[4] Arrazola, P. J., et al. (2005). Serrated chip prediction in numerical cutting models. 8th CIRP Workshop on Modeling of Machining Operations 5, pp. 115-122

[5] Mamalis, A.G., Kundrak, J., et al. (2003). Thermal modeling of surface grinding using implicit finite element techniques. Int. Journal of Advanced Manufacturing Technology, vol. 12, pp. 929-934

[6] Mamalis, A.G., Kundrak, J., et al. (2007). On the finite element modeling of high speed hard turning. Int. Journal of Advanced Manufacturing Technology, vol. 16

[7] Guo, Y.B., Liu, C.R. (2002). 3D FEA Modelling of hard turning. ASME Journal of Manufacturing Science and Engineering, vol. 124, pp. 189-196

[8] Ng E.-G., Aspinwall, D.K. (2002). Modeling of hard part machining. J Mater Process Technol, vol.127, pp. 222-229

[9] Beňo, J., Maňková, I. (2004). Technological and material factors of machining. Vienala Press, Košice, (in Slovak). ISBN 80-7099-701-X, 418

[10] Leopold, J., Neugebauer, R. (2004). A finite element study of the effect of friction on chip- and burr-formation in orthogonal metal cutting. 7th CIRP Int. Workshop on Modeling of Machining Operations 5, pp. 125-132
[11] Maňková, I., Beňo, J. (2007). Introduction to FEM simulation of cutting temperature when turning of AISI 1045 steel. Production Process in Mechanical Engineering - Research Reports, Krakow, pp. 105-110

[12] Maňková, I., Marková, G. (2009). Comparative assessment of hard turned surfaces microgeometry by $2 \mathrm{D}$ and 3D parameters. Acta Mechanica Slovaca, vol.13, pp. 86-93

[13] Zebala, W., Slusarczyk, L. (2006). Aspect of FEM simulation of cutting process. Production Process in Mechanical Engineering - Research Reports, Krakow, pp. 69-74

[14] Demeč, P., Svetlík, J.: (2009) Virtual Machining and its Experiemnatl Verification. Acta Mechanica Slovaca, ISSN 13352393, 13, No 4: 68-73

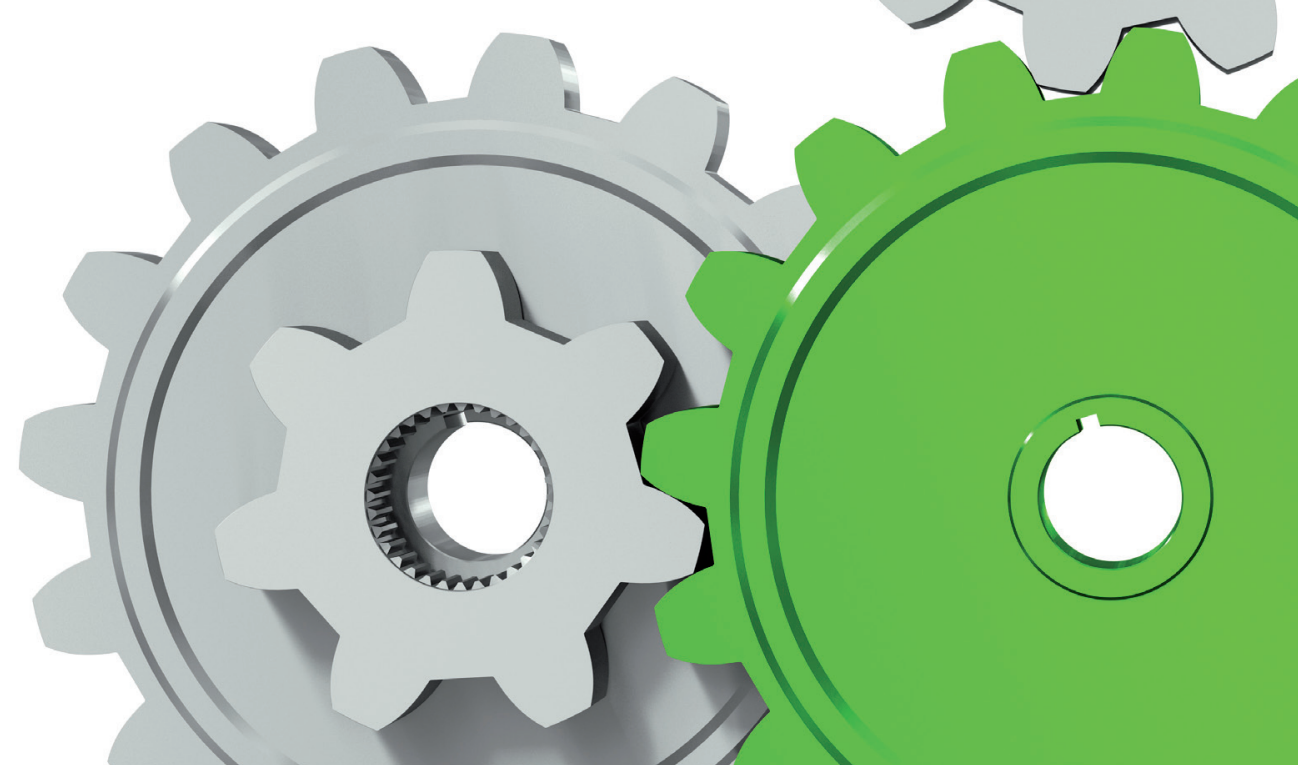

